\title{
Consumer Perceptions of Price (Un)Fairness
}

\author{
LISA E. BOLTON \\ LUK WARLOP \\ JOSEPH W. ALBA*
}

\begin{abstract}
A series of studies demonstrates that consumers are inclined to believe that the selling price of a good or service is substantially higher than its fair price. Consumers appear sensitive to several reference points-including past prices, competitor prices, and cost of goods sold-but underestimate the effects of inflation, overattribute price differences to profit, and fail to take into account the full range of vendor costs. Potential corrective interventions-such as providing historical price information, explaining price differences, and cueing costs-were only modestly effective. These results are considered in the context of a four-dimensional transaction space that illustrates sources of perceived unfairness for both individual and multiple transactions.
\end{abstract}

$F^{i}$ ine restaurants gouge consumers, as evidenced by wine prices that are multiples of the going retail rate. Music on the internet should be freely shared because the recording industry is rapacious in its pricing. Gasoline prices are exorbitant because they are determined more by industry collusion than market forces. Pharmaceutical prices should be regulated due to the obscenely high profits made on prescription drugs and the relatively low prices paid in other countries for the same products. Such beliefs-whether accurate or not-hold great consequence because the profitability of firms is constrained by fear of perceived exploitation (Blinder 1991; Kahneman, Knetch, and Thaler 1986a; Piron and Fernandez 1995) and because consumer satisfaction and price consciousness is shaped in part by perceptions of price fairness (Sinha and Batra 1999).

Despite the importance of perceived price fairness, research on the topic has been sparse. Relevant research that does exist has largely been inspired by the principle of dual entitlement (Kahneman, Knetch, and Thaler 1986b), which argues that fairness perceptions are governed by the belief that firms are entitled to a reference profit and customers are entitled to a reference price. Changes in the status quo price should not be made arbitrarily or merely for the purpose of increasing the firm's profit, such as when prices are raised to take advantage of surplus demand or newly obtained monopoly power. On the other hand, the firm is en-

*Lisa E. Bolton is assistant professor of marketing, the Wharton School, University of Pennsylvania, Philadelphia, 19104-6340 (boltonl@ wharton.upenn.edu). Luk Warlop is associate professor, Katholieke Universiteit Leuven, Leuven, Belgium (luk.warlop@econ.kuleuven.ac.be). Joseph W. Alba is distinguished professor of marketing, University of Florida, Gainesville, 32611-7155 (albaj@dale.cba.ufl.edu). Correspondence: Lisa E. Bolton. The authors appreciate the constructive comments provided by the editor, associate editor, and reviewers. titled to protect its profit when threatened by events such as rising costs. In the classic example, a retail vendor is entitled to raise the price of snow shovels in response to an increase in the wholesale price but not in response to a surge in demand brought about by a snowstorm.

The goal of the present research is to explore a variety of factors that contribute to consumer perceptions of price fairness. We build on the provocative findings of Kahneman et al. (1986b) regarding the principle of dual entitlement but depart from their approach in four ways: (1) Fundamental to dual entitlement is the notion of a reference transaction. Fairness of a given transaction is a function of the characteristics of other transactions or potential transactions. Previous research has focused primarily on the price of a good at a previous time or during a previous transaction. We broaden the treatment of reference points to include not only past prices but also competitor prices and vendor costs. (2) This broader treatment permits us to examine static as well as dynamic environments. For example, how do consumers judge price fairness in the absence of a price change? The principle of dual entitlement is mostly silent on this issue. (3) Although dual entitlement argues that a vendor is entitled to a reference profit, participants in related fairness research are generally provided with price information. Explicit profit information typically is absent, and consumer inferences about a firm's profitability are rarely measured directly. The experiments described here examine profits as well as prices and attempt to obtain greater access to consumer understanding of profitability. (4) Prior research has emphasized the vendor's motivation for altering the status quo, and therefore research on dual entitlement has been dominated by considerations of perceived equity, justice, and ethics (e.g., Bies, Tripp, and Neale 1993; Campbell 1999; Martins and Monroe 1994). In contrast, the present research focuses 
on cognitive determinants of fairness by investigating consumer understanding of markets, the environment, and vendors' constraints.

In common parlance, fairness might refer to the extent to which outcomes are deemed reasonable and just, and transaction fairness might refer to the extent to which sacrifice and benefit are commensurate for each party involved. As a definition of price fairness, we begin with the basic premise that firms are entitled to a reference profit that, from the consumer's perspective, may refer to some reasonable amount above costs. Indeed, Monroe (1990) suggests that the prevalence of cost-plus pricing is driven partly by concerns about perceived fairness. The present research avoids the difficult issue of how to define a reasonable profit and instead focuses on consumer perceptions of the "cost" and "plus" of everyday prices.

We investigate the role of three reference points-past prices, competitor prices, and costs —on fairness judgments. ${ }^{1}$ We characterize these reference points as looking back over time (at past prices), looking across firms (at competitor prices), and looking within the firm (to costs). We are especially interested in understanding the assumptions, inferences, and attributions that consumers make about costs and profits. We assume that once a reference point has been evoked, consumer judgment is guided by attributions regarding the difference between the target price and the reference point. This comparison process drives profit perceptions and price fairness judgments. Prices that compare favorably with the reference point are deemed fair; prices that compare unfavorably are deemed unfair. Prior research provides evidence that perceptions of fairness in turn will influence customer satisfaction (Oliver and Swan 1989) and behavioral intentions (Campbell 1999), but we do not investigate these variables directly.

Given that consumer knowledge of explicit and unambiguous retail price information can be low and may be declining (Estelami, Lehmann, and Holden 2001), it seems reasonable to expect poor appreciation of closely guarded cost and profit information. Although knowledge of profits and costs has not been extensively investigated, consumers are not highly satisfied with the price-profit relationship they perceive to exist among large firms (Business Week 2000). Thus, our guiding hypothesis is that consumer understanding of prices, costs, and profits does not exist at high levels across the population; moreover, we propose that such knowledge levels contribute to consumer perceptions of price unfairness.

\section{LOOKING BACK: PAST PRICES}

Evidence suggests that consumers rely on past prices when judging the appropriateness of current prices and use

\footnotetext{
'We distinguish between a reference point and a reference price. For example, a firm's cost of production may serve as a reference point for assessing the fairness of a retail price. Of course, reference points may be used to form an internal reference price that in turn influences transaction value (e.g., Grewal, Monroe, and Krishnan 1998).
}

current prices to forecast future prices (Briesch et al. 1997; Jacobson and Obermiller 1990; Wall Street Journal 1997). Research also suggests that consumers have a poor understanding of inflation and that their estimates of its effects may be biased in the direction of underestimation (Bates and Gabor 1986; Katona 1975; Kemp 1987, 1991). Such results are consistent with psychophysical research showing that underestimation is common in trend extrapolation of time-series data (e.g., Wagenaar and Sagaria 1975), perhaps due to anchoring effects (cf. Harvey and Bolger 1996). Therefore, we expect that consumers will underestimate rather than overestimate inflationary trends, which in turn will prompt overestimation of seller profits and the perception of unfair pricing.

\section{Experiment 1: Past Prices and Perceived Fairness}

The present and all subsequent experiments reported here employ a scenario paradigm. A purchasing situation is described, and beliefs are measured. A variety of direct and indirect measures are taken across experiments, including absolute and percentage profit (and cost) estimates and price attributions (such as gouging). This measurement approach ensures that the findings are robust to elicitation method and provides greater insight into consumer knowledge structures. Unless otherwise noted, participants were undergraduate students who received course credit in return for their participation. The numbers of participants are reported in tables that accompany the experiments. ${ }^{2}$

Method. Participants were presented with a current and historical price of a polo shirt and were asked to determine whether the-increase in price was fair, given that the historical price was fair. The between-subjects design consisted of three experimental groups (three levels of current price information) and a control group (no current price information). The current price of the shirt $(X)$ was manipulated at three levels $(\$ 34.59, \$ 39.49$, or $\$ 44.79)$, with the middle price of $\$ 39.49$ corresponding to the historical fair price adjusted for inflation (rounded up from $\$ 39.42$ to a price ending in nine). After a short introduction, participants read the following:

Consider the case of a particular brand of polo shirt sold by a particular department store retailer. (The name of the brand and the retailer will not be disclosed. It is best to avoid guessing who they are.) Seven years ago, the retailer sold this brand of polo shirt to consumers at a fair price of $\$ 23$. Since then, inflation and quality have forced the manufacturer to raise its price each year. Simply to cover these costs, the retailer would need to raise its retail price each year by $8 \%$ over each previous year. If you go to the store today, the

\footnotetext{
${ }^{2}$ Across the set of nine laboratory studies reported here, 35 participants gave numerical responses that violated the task instructions. These participants were omitted from the reported analyses, but their inclusion would leave the pattern of results unchanged. An additional 10 participants failed to respond to an individual item but were included in analyses of other dependent variables.
} 
TABLE 1

ATTRIBUTIONS AND FAIR PRICE ESTIMATES AS A FUNCTION OF INFLATION AND CURRENT PRICE: EXPERIMENT 1 (\$)

\begin{tabular}{|c|c|c|c|c|}
\hline Current price & Median (and range) & Absorbing & Correct price & Gouging \\
\hline 34.59 (below fair price) & $\begin{array}{c}35.88 \\
(24.84-50.00)\end{array}$ & $\begin{array}{c}39.67(4.23) \\
n=19^{\circ}\end{array}$ & $\begin{array}{c}34.59 \\
n=27^{\mathrm{b}}\end{array}$ & $\begin{array}{c}29.28^{*}(3.61) \\
n=14^{b}\end{array}$ \\
\hline 39.49 (correct fair price) & $\begin{array}{c}35.00 \\
(25.00-45.00)\end{array}$ & $\begin{array}{c}43.31 *(1.56) \\
n=5^{\mathrm{c}}\end{array}$ & $\begin{array}{c}39.49 \\
n=39^{a}\end{array}$ & $\begin{array}{c}32.36^{*}(4.21) \\
n=19^{b}\end{array}$ \\
\hline 44.79 (above fair price) & $\begin{array}{c}36.99 \\
(25.00-56.64)\end{array}$ & $\begin{array}{c}51.2^{*}(5.32) \\
n=3^{c}\end{array}$ & $\begin{array}{c}44.79 \\
n=21^{c}\end{array}$ & $\begin{array}{c}36.18^{*}(4.31) \\
n=39^{a}\end{array}$ \\
\hline Open-ended & $\begin{array}{c}37.00 \\
(25.00-65.00)\end{array}$ & & $\begin{array}{c}38.54(7.47) \\
n=63^{\mathrm{d}}\end{array}$ & \\
\hline
\end{tabular}

NoTE.-Superscript $a=$ data in cell represents true response; superscript $b=$ underestimated inflation; superscript $c=0$ overestimated inflation; superscript $d$ $=39$ underestimated, 16 overestimated.

*Significantly different from the correct value (all $p ’ s<.05$ ).

price you will see on this polo shirt is $\$ X$. Based on your first impression, please check one of the three responses below $(a, b$, or $c)$ and answer the remainder of the question if necessary.

a) I think that the retailer has absorbed some of the manufacturer's price increase. In order to maintain the same fair profit as 7 years ago, the retailer should raise the price from $\$ X$ to $\$$

b) I think the retailer has neither absorbed any of the manufacturer's price increase nor tried to make extra profit. Thus, $\$ X$ is an appropriate price to charge.

c) I think the retailer has added to the manufacturer's price increase and is trying to make additional profit. In order to maintain the same fair profit as 7 years ago, the retailer should lower the price from $\$ X$ to $\$$

A fourth (control) group of participants was not given a current price but instead was asked the open-ended question "What do you think would be a fair price for the retailer to charge consumers for this polo shirt today?"

Results. A categorical analysis indicates a propensity to underestimate the fair price (see table 1). Among participants provided with a specific current price, a greater number underestimated $(32.3 \%)$ than overestimated inflation $\left(15.6 \% ; \chi^{2}(2)=34.21, p<.001\right)$. Similarly, among participants who were asked only for an open-ended response, significantly more $(61.9 \%)$ underestimated than overestimated the fair price $\left(25.4 \% ; \chi^{2}(2)=21.27, p<.001\right)$. As might be expected, participants' responses in the experimental groups were influenced by the stated current price $\left(\chi^{2}(4)=32.47, p<.001\right)$. When a low current price was given, participants were more likely to underestimate inflation than when a high current price was given. The current retail price appeared to act as an anchor, such that fair price estimates varied with the current going rate $(F(2,90)=$
$20.68, p<.001) .^{3}$ More important, the anchoring effect of the current price was insufficient to compensate fully for perceptions of unfairness or gouging. When the current price was the fair price, more participants underestimated than overestimated inflation (19 vs. 5 out of 63 participants), and the degree of underestimation was considerable $(M=$ $\$ 32.36$ vs. a true fair price of $\$ 39.42 ; t(18)=-7.31, p<$ $.001)$. Even when provided with a very high current price anchor (\$44.79), participants insufficiently adjusted for inflationary effects. That is, the observed estimate $(M=$ $\$ 36.18)$ is significantly lower than the true value $(t(36)=$ $-4.57, p<.001)$.

\section{Discussion}

In this study we measured attributions about a current price in the context of a historical price. The results indicate that when faced with rising prices over time, consumers harbor suspicions about vendor gouging. It is reasonable to assume that such beliefs may ultimately result in nonpurchase, bargaining, or search for alternative vendors.

Although the retrospective judgments consumers make when comparing current to past prices may lead to dissatisfaction, analogous underestimation of inflation's effects can have dire consequences when judgments are made in prospect. We illustrate this problem in a series of followup studies conducted in the context of college tuition, where failure to adjust for inflationary effects can result in lack of financial preparedness for an essential consumer purchase.

In the first follow-up study, participants were asked to estimate the annual savings required to pay for the cost of a college education 10 years in the future. Thirty-eight participants were given the current cost of an education, the inflation rate (manipulated between subjects to be either $3 \%$ or $9 \%$ ), and the interest rate accrued on savings (manipulated

\footnotetext{
${ }^{3}$ This analysis includes only participants who judged that the retailer was absorbing or gouging (since only these participants were asked to provide their own estimate of fair price). The analysis also revealed a main effect of choice (absorbing or gouging; $F(1,90)=104.73, p<.001$ ), as expected.
} 
within subject to be either $0 \%$ or equal to the inflation rate). As expected, participants underestimated the required savings rate. The proportion of required savings accrued at the end of 10 years was 0.87 and 0.65 in the $3 \%$ and $9 \%$ conditions, respectively $(F(1,36)=6.08, p<.02)$. Hence, the tendency to underestimate inflation occurs in prospect as well as in retrospect. It is also noteworthy that the savings interest rate did not moderate the tendency toward underestimation $(F<1)$. (Many participants apparently believed that saving $10 \%$ of the current cost per year at the rate of inflation was sufficient.)

For important decisions, consumers may possess or seek historical information, but not all historical data are equally helpful. Although recent prices and price changes are likely to be most salient, remote data best reveal the exponential nature of inflation (cf. Wagenaar and Timmers 1979). In a second follow-up study, participants were asked to predict the cost of a college education 10 years hence. They were given the current price of a college education $(\$ 99,860)$ and historical price information that reflected a constant inflation rate (manipulated between subjects to be either $3 \%$ or $9 \%$ ). The type of historical price information provided to participants was manipulated between subjects at three levels: remote data (from 10 years ago only), recent data (from the previous three years), or both recent and remote data. The data were computed based on the stated current price and rate of inflation. An analysis based on the percentage deviation from the correct response revealed a main effect of inflation rate $(F(1,162)=102.98, p<.001)$, a main effect of type of data $(F(2,162)=3.27, p=.04)$, and a nonsignificant interaction $(F(2,162)=1.41, p=.25)$. Prices were uniformly underestimated and were especially inaccurate at the higher inflation rate (e.g., $71 \%$ of the correct value when inflation was $9 \%$ and recent data were provided). Moreover, estimates made in the context of recent prices were significantly lower and less accurate than estimates made in the context of remote prices $(F(1,162)=6.55$, $p=.01$ ).

It is not clear that consumers appreciate the benefits of adopting a longer time horizon. We investigated this possibility in a third follow-up study. Participants were asked to predict the annual cost of college 10 years hence based on a stated current cost and a steady-state inflation rate for the previous 10 years. Before doing so, however, they were given the opportunity to view a single price from any of the preceding 10 years. Our objective was to assess participants' sensitivity to the salutary effect of adopting a long time horizon (i.e., to search remote prices). Results produced a search distribution that was largely bimodal. Of the 85 participants, $42.4 \%$ searched for price data from one to three years in the past, with the majority searching only one year back; an identical percentage searched eight to 10 years in the past, with the majority searching 10 years back. Insofar as recent data harm predictive accuracy, the majority of participants in this study can be characterized as having searched suboptimally.

Taken together, the results suggest that consumers may be poor assessors in prospect and retrospect of the effects of inflation on prices. Our respondents, who likely possessed above-average computational abilities, misestimated inflation's impact despite the provision of explicit, realistic, and personally relevant information. We speculate that in most environments in which inflation exists above nominal levels, sticker shock and perceptions of unfairness may ensue. More severe consequences loom when miscalculation results in suboptimal behavior, such as undersaving for an important future purchase.

\section{LOOKING ACROSS: COMPETITOR PRICES}

Past prices are not the only nor even the dominant influence on price perceptions (Mayhew and Winer 1992; Rajendran and Tellis 1994). As Kahneman et al. (1986b) note, prevailing competitor prices can serve as reference transactions, especially when a transaction history with a particular vendor does not exist. In commodity markets, prices are kept low because attempts to price above the going rate can stimulate feelings of unfairness and customer defection (e.g., Frey and Pommerehne 1993; Lichtenstein and Bearden 1989). The case of noncommodity markets is not often addressed. The principle of dual entitlement suggests that price differences can be justified by cost differences, and consumer research suggests that price differences frequently are interpreted in terms of quality differences (which presumably correspond to cost differences). We do not question the reasonableness of price-quality inferences, particularly in competitive markets. However, in the larger environment, many other factors contribute to price and profit. In this and the following section we examine consumer understanding of, and reaction to, these factors. In most instances we hold product quality constant while assessing (1) attributions consumers make regarding prices and profits or (2) reactions to explicit price and profit levels of competing vendors who differ on nonproduct dimensions.

\section{Experiment 2: Profit versus Cost Attributions}

Competing retail stores may sell the same brand but offer different levels of service or convenience that entail different costs or margin requirements. The present experiment investigates the effect of store differences on judgments of price fairness. By manipulating the explicitness of differences in retail tactics, we assess whether consumers spontaneously acknowledge store differences. Prior research suggests that consumers are somewhat sensitive to store differences (Grewal and Baker 1994; Thaler 1985); to our knowledge, however, the extent to which the benefits offered by different stores is perceived to offset price differences has not been examined vis-à-vis fairness.

Method. The experiment used a 2 (Store Type) $\times 2$ (Benefit Cue) $\times 2$ (Product Replicate) mixed design. Product replicate was manipulated between subjects (ice cream vs. clothing), and store type was manipulated within subject 
TABLE 2

PRICE AND PROFIT ESTIMATES AS A FUNCTION OF STORE PRICE IMAGE: EXPERIMENT 2

\begin{tabular}{|c|c|c|c|c|c|c|}
\hline Product & Store price image & $n$ & $\begin{array}{c}\text { Actual price } \\
(\$)\end{array}$ & $\begin{array}{l}\text { Fair price } \\
(\$)\end{array}$ & $\begin{array}{c}\text { Profit } \\
\text { (out of } \$ 1 \text { ) }\end{array}$ & $\begin{array}{c}\text { Surcharge } \\
\text { (actual minus } \\
\text { fair price) }\end{array}$ \\
\hline Ice cream & Grocery (inexpensive) & 23 & $3.64(.60)$ & $3.30(.56)$ & $.22(.15)$ & $.35(.32)$ \\
\hline lce cream & Convenience (expensive) & & $4.13(.86)$ & $3.46(.76)$ & $.36(.19)$ & $.66(.34)$ \\
\hline Clothing & Discount (inexpensive) & 22 & $35.14(5.84)$ & $32.89(6.14)$ & $.19(.10)$ & $2.25(4.01)$ \\
\hline Clothing & Department (expensive) & & $44.13(8.42)$ & $35.89(6.41)$ & $.32(.17)$ & $8.25(4.29)$ \\
\hline
\end{tabular}

(inexpensive vs. expensive store price image). Thus, participants were asked for reactions concerning a pint of ice cream at a grocery store and convenience store or an article of clothing at a discount and a department store. The costs/ benefits offered by the competing stores (e.g., location, atmosphere, service) were either cued or not cued, also between subjects. After viewing the stimulus, participants were asked to estimate the actual and fair prices and the profit margins of each store in side-by-side judgments. For example, the scenario from the clothing condition, with the benefit cue shown in square brackets, read as follows:

The retail industry is composed of many types of stores. Even for stores that sell similar merchandise, large differences exist among competing retailers. Without mentioning specific examples, most shoppers can name several department stores. There are also many discount stores that may sell similar clothing (and often sell the same brands). [Department stores tend to offer greater selection, more service, and a more pleasant in-store environment.] Imagine an identical item sold at both types of stores. For example, this item may be a shirt or blouse or slacks. The same manufacturer sells the item to both stores for an identical price. In this instance, imagine that the price is $\$ 25$. On the lines below, please estimate the following:

1) How much will each store charge the consumer for the item?

2) What do you feel would be a fair price for each store to charge?

3) For each dollar that the store takes in at its true prices, how much is left over in profit after each store has covered all of its costs?

ก

Results and Discussion. Table 2 indicates an identical pattern of results for each stimulus replicate (analyzed separately due to heterogeneity of variance in price estimates). As expected, actual price estimates were higher for the expensive store than for the inexpensive store $(F(1,21)=$ $21.15, p<.001$, for ice cream; $F(1,20)=100.46, p<$ .001 , for clothing). Similarly, estimates of the fair price were higher for the expensive store than for the inexpensive store $(F(1,21)=8.10, p<.01$, for ice cream; $F(1,20)=$ 24.53, $p<.001$, for clothing). There were no significant effects of the benefit cue on actual or fair price estimates. ${ }^{4}$ We surmise that the within-subject manipulation of store comparison made the store differences so salient that the cue had no incremental effect. (In experiments reported later, cost cues are shown to exert a much larger influence.) The higher estimated actual and fair prices for the expensive store suggest that participants spontaneously acknowledged differences between stores, consistent with Thaler's (1985) willingness-to-pay measures.

More interesting are the profit-related measures. Although participants conceded higher prices to the expensive stores, they nonetheless thought that the prices at the expensive stores were less fair. The unfair surcharge (actual price minus fair price) was greater for the expensive store than for the inexpensive store $(F(1,21)=20.61, p<.001$, for ice cream; $F(1,20)=45.67, p<.001$, for clothing). Similarly, profit estimates (per dollar of sales) were higher for the expensive store $(F(1,16)=41.05, p<.001$, for ice cream; $F(1,18)=23.29, p<.001$, for clothing). The benefit cue again had no effect on either surcharge or profit. ${ }^{5}$ Although consumers may be willing to pay higher prices to a vendor who carries higher costs (cf. Thaler 1985), profit and fairness perceptions may favor a less expensive competitor.

Overall, participants expected prices to differ by store and judged part of this price difference as fair-presumably due to store cost differences, inasmuch as the cost of good sold (CGS) was held constant. Cueing the benefits of each store had no incremental effect. From an attribution standpoint, it appears that respondents attributed the expected price differential between the expensive and inexpensive store more to profit than to cost. That is, when accounting for the expected difference in actual price, the estimated profit differences exceeded the estimated cost differences by a factor of two (ice cream) or three (clothing). In terms of an attri-

\footnotetext{
${ }^{4}$ For completeness, two (marginal) exceptions are reported. For clothing, neither the benefit cue nor its interaction with store type were significant for fair price and actual price estimates (all $F$ 's $<1$ ). For ice cream, the benefit cue marginally reduced actual price $(F(1,21)=3.00, p=.10$; interaction $F<1)$ and fair price estimates $(F(1,21)=3.49, p=.08$; interaction $F(1,21)=1.50, p=.23)$.

${ }^{5}$ Most important, the benefit cue had no effect on profit estimates for clothing or ice cream (all $F$ 's $<1$ ). The benefit cue also had no effect on the surcharge for clothing $(F<1$; interaction $F(1,20)=2.37, p=.14)$ or ice cream (all $F$ 's $<1$ ).
} 
TABLE 3

COST AND PROFIT ESTIMATES (DEPARTMENT MINUS DISCOUNT STORE) AS A FUNCTION OF BRAND CUE: EXPERIMENT 3

\begin{tabular}{|c|c|c|c|c|c|c|c|}
\hline Brand cue & $n$ & $\begin{array}{l}\text { Price } \\
(\$)\end{array}$ & $\begin{array}{l}\text { Cost of good sold } \\
(\$)\end{array}$ & $\begin{array}{l}\text { Other } \\
(\$)\end{array}$ & $\begin{array}{l}\text { Profit } \\
(\$)\end{array}$ & $\%$ profit & Fairness \\
\hline Different & 51 & $\begin{array}{r}20.49^{\star} \\
(8.95)\end{array}$ & $\begin{array}{r}6.97^{*} \\
(6.60)\end{array}$ & $\begin{array}{c}4.45^{*} \\
(4.51)\end{array}$ & $\begin{array}{r}9.07^{\star} \\
(5.68)\end{array}$ & $\begin{array}{c}2.10 \\
(12.02)\end{array}$ & $\begin{array}{r}-1.84^{*} \\
(1.60)\end{array}$ \\
\hline Same & 45 & $\begin{array}{r}19.38^{*} \\
(10.22)\end{array}$ & $\begin{array}{l}3.47^{*} \\
(5.92)\end{array}$ & $\begin{array}{r}4.36^{*} \\
(4.82)\end{array}$ & $\begin{array}{l}11.56^{*} \\
(9.68)\end{array}$ & $\begin{array}{r}8.13^{*} \\
(12.09)\end{array}$ & $\begin{array}{r}-2.19^{*} \\
(1.59)\end{array}$ \\
\hline
\end{tabular}

*Significantly different from zero $(p<.05)$.

bution hierarchy, profit attributions dominated store cost attributions.

The magnitude of the per-dollar profit estimates also is notable. A result that is observed repeatedly in subsequent experiments is that consumers are naive with respect to retail profitability and the opportunity to generate high profit margins in competitive marketplaces. Given the high margins estimated by these participants, skepticism regarding the fairness of retail prices is natural.

\section{Experiment 3: Profit, Cost, and Quality Attributions}

In the preceding experiment the competing stores offered the same brands and therefore price-difference attributions were constrained to profit and service costs. In the present experiment we allowed participants to make quality attributions as well by manipulating whether the brands in the competing stores were identical. As noted, prior research suggests that quality is the default attribution when different brands possess different prices. In a retail context, quality competes with profit and other costs as possible attributions.

Method. The experiment employed a 2 (Store Type) $\times$ 2 (Benefit Cue) $\times 2$ (Brand) mixed design. Brand was manipulated between subjects (same vs. different brand) and store type was manipulated within subject (department vs. discount store). Thus, participants were asked for reactions concerning a polo shirt of either the same or different brand sold at a department and discount store. The costs/benefits offered by the competing stores were either cued or not cued, also between subjects. The stimulus frame was as follows:

You are out shopping one day for a polo shirt. You visit a department store. While there, you see a polo shirt. Later the same day, you visit a discount store. [While there, you see the exact same polo shirt (same brand, same style, same fabric and color, etc.). / While there, you see another polo shirt (a different brand)]. [You also notice that the department store has more selection and service, as well as a more pleasant in-store environment (compared to the discount store). / omit] For each store, please estimate the following:

What is the price you pay for the polo shirt in each store?

a) How much of the price you pay does the store use to pay the manufacturer for the item? b) How much of the price you pay goes to cover other costs that the store has?

c) How much of the price you pay is left over as profit made by the store on this item?

How fair do you think the store's price is?

After viewing the stimulus, participants made side-byside judgments for the polo shirt at the department and discount stores. Participants were asked to provide numerical estimates of price, CGS, other costs, and profits, and to assess price fairness on a seven-point scale.

Results. For simplicity of presentation, table 3 presents the mean difference scores between the department and discount store for each dependent measure. The results are collapsed across benefit cue, which again had no effect. ${ }^{6}$ As expected, estimates for the total price of the polo shirt were higher in the department store than the discount store $(F(1,92)=406.6, p<.001)$ but did not vary by condition. Also as expected, estimates for CGS depended on the store $(F(1,92)=65.53, p<.001)$ and its interaction with brand $(F(1,92)=7.08, p<.01)$. The CGS estimates were larger for department than discount stores, especially when the stores carried different brands. Regardless of whether the stores carried identical or different brands, estimates for other costs were higher for department stores than discount stores $(F(1,92)=83.7, p<.001)$, as were profit estimates $(F(1,92)=164.3, p<.001)$ in absolute dollars. Further, the differences in perceived fairness corresponded to differences in perceived profits: higher prices and profits were associated with lower fairness.

In terms of the attribution hierarchy, the results are straightforward. When stores carry the same brand (as in experiment 2), the large expected price difference between the department and discount stores was attributed foremost to profit and then to other costs, with again an almost three times greater allocation to profit. When stores carried different brands and a quality attribution was possible, profit again was dominant. However, quality (CGS) dominated other costs. It is apparent that consumers readily make pricequality inferences.

Finally, an interesting effect is observed when profit is

\footnotetext{
${ }^{6} \mathrm{~A}$ lone (marginal) exception was that the fairness advantage of discount stores over department stores was reduced when store differences were cued $(F(1,90)=3.68, p=.06)$.
} 
converted to a percentage of price. Percentage profits were generally quite large (around $40 \%$ ) and were larger in the department store than in the discount store $(F(1,92)=$ $16.95, p<.001)$. Moreover, this difference in percentage profit was greater for same brands than different brands $(F(1,92)=5.83, p=.02)$. Indeed, when quality attributions were possible with different brands, the department and discount stores were viewed as generating the same percentage profit $(t(50)=1.25, p>.10)$. This result is noteworthy when considered in the context of the fairness ratings. Fairness was viewed as uniformly higher at the discount store $(F(1,90)=153.7, p<.001)$. Thus, when quality attributions were possible, it seems that judgments were driven more by the absolute profit differences (almost double for department versus discount stores) than the percentage profit differences (which were small). The dual entitlement principle proposes that sellers are entitled to a reference profit but is silent with respect to whether consumers make finer distinctions concerning absolute versus percentage profits when assessing fairness. A failure to relate fairness to percentage profit differences could be due to several factors, including a naive understanding of market constraints or retail accounting. The next experiment pursues this possibility.

\section{Experiment 4: Not All Equal Profits Are Equally Fair}

Some retail strategies are primarily determined endogenously. For example, some retailers incur higher costs (e.g., by providing better service or carrying riskier inventory) that are passed on to customers in the form of higher prices. Other strategies may be determined exogenously. For example, firms with a narrow geographical customer base will suffer lower inventory turnover and therefore must charge higher prices to make a profit. In the present experiment, we presented price differences between two stores and attributed these differences to various factors (i.e., product quality, non-CGS costs, customer base, inventory risk, and margin/volume strategy). Unlike the preceding experiment, net profit margin was explicitly described as equal at the two stores. Our objective was to assess the extent to which participants would accommodate forces that are largely beyond the retailers' control when estimating fair prices. We hypothesized that price differences not exclusively attributable to quality (such as other costs and risk) would be perceived as unfair. We also expected that prices based on an intentional high-margin strategy would be judged as less fair than prices based on unavoidable constraints faced by the firm. The more interesting but less predictable result concerns the precise way in which these latter firms are viewed.

Method. Participants were given prices for blouses at two stores. At store A, the blouse was priced at $\$ 29.95$; at store B, the blouse was priced at $\$ 39.95$. Overall costs and net profit were held constant. Respondents were then given an explanation (manipulated between subjects at five levels) for the price difference and asked to assess the fair price of the blouse at each store. In all conditions, the explanation began as follows:

We are interested in your views, as a consumer, on the fairness of store finances and pricing. As you know, stores make a profit from selling goods and overall profit is a function of many factors. Consider the case of two stores.

In the quality explanation condition, the scenario attributed the higher price at store B to quality. It controlled for other store differences by equating service and other costs, overall revenue, and net profit as follows:
Both stores have the same level of service and other costs, the same overall sales revenue, and the same net profit. Both stores sell blouses. Store A charges $\$ 29.95$; Store B charges $\$ 39.95$. Store A charges a lower price because it carries a lower quality blouse. The store pays less to the manufacturer for the blouse; as a result, the same markup leads to a lower price than in Store B. Store B carries a higher quality blouse. The store pays the manufacturer more for this blouse; with the same markup as Store A, its prices are higher.

In the other cost condition, the scenario attributed the higher price at store B to other costs. It controlled for other store differences by equating quality, sales revenue, and net profit as follows:

Both stores have the same overall sales revenue and the same net profit. Both stores sell the exact same blouse (same brand, same quality, same style, same cost paid to the manufacturer). Store A charges $\$ 29.95$; Store B charges $\$ 39.95$. Store A charges a lower price because its other costs (service, admin, rent, etc.) are lower. (For example, it offers less service, rent is lower in its location, etc.) Store B charges a higher price because it has to cover higher other costs. (For example, it offers better service, has higher rental costs in its location, etc.). As a result, Store $B$ has to charger a higher price to make the same profit as Store A.

In the risk condition, the scenario attributed the higher price at store B to risky inventory. It controlled for other store differences by equating service, quality, sales revenue, and net profit as follows:

Both stores have the same level of service, the same costs and overall sales revenue, and the same net profit. Both stores sell blouses of the same quality and pay the same cost to their manufacturers. Store A charges $\$ 29.95$; Store B charges $\$ 39.95$. Store A charges a lower price because it faces less risk that it will not able to sell its inventory. Store B carries riskier inventory. (For example, its blouses may be seasonal or very fashion-forward or from new/unknown designers or manufacturers.) As a result, it faces more risk that it will not be able to sell its inventory and will have to dump blouses at the end of the season. Store B covers this risk by charging higher prices for the same quality goods than Store A.

In the customer base condition, the scenario attributed the higher price at store $\mathrm{B}$ to a narrow customer base due to 
geography. It controlled for other store differences by equating service, quality, sales revenue, and net profit as follows:

Both stores have the same level of service, the same costs and overall sales revenue, and the same net profit. Both stores sell the exact same blouse (same brand, same quality, same style). Store A charges $\$ 29.95$; Store B charges $\$ 39.95$. Store A charges a lower price because it has a broad customer base due to its geography. The broad customer base results in higher turnover so Store A can charge lower prices to make the same profit as Store B. Store B, with its narrow customer base due to its geography, has lower turnover so must charge higher prices to make the same profit.

In the margin/volume strategy condition, the scenario attributed the price difference to a high margin strategy at store B and a volume strategy at store A. It controlled for other store differences by equating service, quality, sales revenue, and net profit as follows:

Both stores have the same level of service, the same costs and overall sales revenue, and the same net profit. Both stores sell the exact same blouse (same brand, same quality, same style). Store A charges $\$ 29.95$; Store B charges $\$ 39.95$. Store A charges a lower price because it follows a "volume strategy." It charges a lower price, which increases sales; with a lower margin per sale but higher volume of sales, it makes the same profit as Store B. Store B, following a "margin strategy," charges a higher price; its lower volume of sales is offset by a higher margin in order to make the same profit.

Following presentation of the scenario, participants were shown a table summarizing the main points of the scenario and asked to generate an estimate of the fair price at each store as follows (shown here for the quality condition only):

Please take a moment to consider these stores. What do you think is a fair price at each store? (Enter a $\$$ amount for each store.)

\begin{tabular}{|c|c|c|c|c|}
\hline Store A & Quality & $\begin{array}{c}\text { Net Profit } \\
\text { on Overall } \\
\text { Revenue* } \\
5 \%\end{array}$ & $\begin{array}{c}\text { Price Charged } \\
\text { For Blouse } \\
\$ 29\end{array}$ & $\begin{array}{l}\text { Fair } \\
\text { Price } \\
\$\end{array}$ \\
\hline re B & Higher & $5 \%$ & $\$ 39.95$ & $\$$ \\
\hline & Both store & $\begin{array}{l}\text { ve the san } \\
\text { in } \$ \text { or } \% \text {. }\end{array}$ & & san \\
\hline
\end{tabular}

Results and Discussion. An ANOVA conducted on the differences in fair-price estimates revealed a significant omnibus effect of condition $(F(4,92)=6.92, p<.001)$. As the pattern of means in table 4 reveals, a quality explanation for price differences led to fair prices that differed by approximately $\$ 10(t(18)=1.12, p=.14)$, which is the appropriate amount if participants fully accept the explanation for the price difference between stores. In all other conditions, the fair price differences were less than $\$ 10$ (all

\section{TABLE 4}

FAIRNESS DIFFERENCES AS A FUNCTION OF STORE STRATEGIES AND CONSTRAINTS: EXPERIMENT 4

\begin{tabular}{lcc}
\hline \hline Strategy/constraint & $n$ & $\begin{array}{c}\text { Fair price difference } \\
\text { (store B minus store A) }\end{array}$ \\
\hline Quality & 19 & $\begin{array}{l}10.79(3.08) \\
\text { Customer base }\end{array}$ \\
Risk & 20 & $t(18)=\begin{array}{l}1.12, p=.14 \\
6.95^{*}(4.25)\end{array}$ \\
Other costs & 19 & $t(19)=\begin{array}{l}3.21, p=.002 \\
5.79^{*}(4.29)\end{array}$ \\
Margin/volume strategy & 19 & $t(18)=\begin{array}{l}4.28, p<.001 \\
5.00^{*}(5.14)\end{array}$ \\
& 20 & $t(18)=4.24, p<.001$ \\
& & $t .20^{*}(4.47)$ \\
& & $t(19)=5.80, p<.001$ \\
\hline
\end{tabular}

*Significantly different from $\$ 10$.

$p$ 's $<.01)$. As expected, a planned contrast of the quality condition against the other cost, risk, and customer base conditions was significant $(F(1,92)=18.41, p<.001)$, indicating that the latter explanations were less acceptable than a quality explanation. In addition, a planned contrast of the margin/volume strategy condition to the nonquality conditions indicates that nonquality explanations are as unacceptable as an intentional margin-strategy explanation $(F(1,92)=2.37, p=.13)$.

To summarize, consumers appear willing to grant a higher price in return for commensurate quality. Consumers appear least willing to grant a higher price arising from a firm's optional and endogenously driven strategy to make profits via high margins rather than high volume. Even when a higher price results from factors beyond a firm's control, consumers appear unwilling to grant the entire amount required by the firm to compete. For example, participants in the risk condition were unwilling to accept the same high price as participants in the quality condition even though (a) the overall profits at the high-priced store in each condition were equal, $(b)$ the overall profits at the high-priced store in each condition were equal to each store's lower priced competitor, $(c)$ the absolute profit margins were low, and $(d)$ the reason for the higher price was beyond the firm's control. Inventory risk at a fashion store is a cost of doing business.

Taken together, these experiments suggest that consumers take into account not only why (Campbell 1999) but also how stores obtain their profit when judging fairness. The dual entitlement principle states that sellers are entitled to a reference profit, but it does not speak to the how or why of it. Apparently, not all equal profits are equally fair.

\section{LOOKING WITHIN: THE FIRM'S COSTS}

Aside from reference transactions, the perceived fairness of a price is likely to be influenced by the perceived cost of a good to the vendor (Bearden, Carlson, and Hardesty 2003; Thaler 1985). Experiments 2 and 3 showed that, although participants were not indifferent to the costs incurred by dif- 
TABLE 5

STORE COST AND PROFIT ESTIMATES (OUT OF \$1) IF LABOR IS CUED: EXPERIMENT 5

\begin{tabular}{|c|c|c|c|c|c|c|}
\hline Store & $n$ & Labor cued & Cost of good sold & Labor cost & Other & Profit \\
\hline Burdines & 40 & Yes & $\begin{array}{c}32.38 \\
(17.81)\end{array}$ & $\begin{array}{c}22.90 \\
(11.81)\end{array}$ & $\begin{array}{l}13.93 \\
(7.62)\end{array}$ & $\begin{array}{c}30.80 \\
(15.22)\end{array}$ \\
\hline Burdines & 44 & No & $\begin{array}{c}41.57 \\
(16.64)\end{array}$ & . . & $\begin{array}{c}27.70 \\
(13.92)\end{array}$ & $\begin{array}{c}30.73 \\
(15.33)\end{array}$ \\
\hline Limited & 42 & Yes & $\begin{array}{c}32.29 \\
(11.95)\end{array}$ & $\begin{array}{c}23.36 \\
(9.12)\end{array}$ & $\begin{array}{l}16.90 \\
(8.83)\end{array}$ & $\begin{array}{c}27.45 \\
(15.81)\end{array}$ \\
\hline Limited & 44 & No & $\begin{array}{c}36.68 \\
(16.55)\end{array}$ & . . & $\begin{array}{c}31.45 \\
(14.80)\end{array}$ & $\begin{array}{c}31.86 \\
(17.70)\end{array}$ \\
\hline Wal-Mart & 40 & Yes & $\begin{array}{c}38.05 \\
(17.05)\end{array}$ & $\begin{array}{c}22.20 \\
(8.96)\end{array}$ & $\begin{array}{c}13.80 \\
(7.76)\end{array}$ & $\begin{array}{c}25.95 \\
(17.83)\end{array}$ \\
\hline Wal-Mart & 44 & No & $\begin{array}{c}39.45 \\
(17.13)\end{array}$ & $\cdot \cdot$ & $\begin{array}{c}29.52 \\
(14.10)\end{array}$ & $\begin{array}{c}31.02 \\
(15.56)\end{array}$ \\
\hline Publix & 47 & Yes & $\begin{array}{c}41.62 \\
(18.00)\end{array}$ & $\begin{array}{c}24.28 \\
(11.32)\end{array}$ & $\begin{array}{l}14.21 \\
(8.88)\end{array}$ & $\begin{array}{c}19.89 \\
(14.54)\end{array}$ \\
\hline Publix & 43 & No & $\begin{array}{c}45.47 \\
(20.23)\end{array}$ & $\cdot \cdot$ & $\begin{array}{c}28.51 \\
(12.41)\end{array}$ & $\begin{array}{c}26.02 \\
(14.50)\end{array}$ \\
\hline
\end{tabular}

ferent types of retailers, estimated profits of retailers were quite high and estimated non-CGS costs were relatively low. Experiment 4 showed that participants were more inclined to accept quality or CGS explanations than other explanations when comparing retail prices. Insofar as CGS is the most salient cost, other costs may be ignored and overall profits may be overestimated. Such an outcome would hold even in the presence of reference transactions once the effect of price change is removed. That is, even when a price change is deemed fair, the absolute price may nonetheless be perceived as too high given the perceived profits of the firm. The results reported by Kahneman et al. (1986b) suggest that consumers are sensitive to unchanging costs in the face of a price increase. An obvious question concerns the extent to which costs-and different categories of costs-are considered spontaneously when judging prices.

\section{Experiment 5: Cueing a Salient Cost}

An exploratory study examined the effect of cueing a seemingly salient cost on profit estimates for retail stores. Specifically, we asked participants to estimate CGS, other costs, and profit while manipulating whether labor was identified as a separate cost category.

Method. Participants were presented with the name of a retail store and were asked to estimate various cost categories. A between-subjects store-replicate manipulation was included for generalizability. The replicates were a department store (Burdines), a discount store (Wal-Mart), a specialty store (Limited), and a grocery store (Publix), all of which were local to the participant population. The cueing manipulation consisted of isolating labor as a separate line item in the cued condition and omitting any mention of labor in the uncued condition. A sample stimulus scenario using the Publix replicate in the cued condition is reproduced below.
We are interested in your impressions of finances at a retail store. The store is Publix. We would like your estimate of the proportion of Publix's revenue that goes to cover cost of goods sold, the proportion that goes to cover labor costs, the proportion that goes to cover all remaining costs, and how much is left as Publix's profit (before taxes). (Cost of goods sold refers to the money the store pays to its suppliers for the goods it sells. Labor refers to the money the store spends to pay its employees.) On the lines below you see a simplified version of a Publix income statement. Consider one dollar of revenue. What is your estimate of how much of each dollar in sales is allocated to each of these categories?

Cost of Goods Sold:

Labor Costs:

All Other Costs:

Profits:

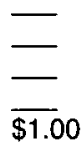

Results. As shown in table 5, profit estimates were high but also varied across replicates $(F(3,336)=4.22, p<$ $.01)$. Logically, there should be no effect of cueing labor on profit estimates because labor costs should be deducted entirely from total other costs. Nonetheless, cueing labor reduced profit estimates $(F(1,336)=5.16, p=.02)$, suggesting that participants did not spontaneously take labor costs fully into account when estimating profits. As expected, other costs did decline when labor was cued $(F(1,336)=138.78, p<.001)$, although insufficiently to account for the full amount of labor cost estimates. Instead, a portion of labor costs was also deducted from CGS $(F(1,336)=6.53, p=.01)$. Whereas CGS varied as a function of the store $(F(3,336)=4.43, p<.01)$, other costs $\operatorname{did} \operatorname{not}(F(3,336)=1.14, p=.33)$.

Overall, participants' understanding of retail costs seemed malleable, but perceptions of profit were somewhat firm. 
The judgments may best be described as quasi-rational. Labor costs were not fully taken into account, as indicated by the reduction in profits when labor was cued. Moreover, CGS estimates were reduced when labor was cued, suggesting a certain stickiness to profit perceptions.

\section{Experiment 6: Generalization to the Population}

Although the participants in the preceding experiment were relatively sophisticated vis-à-vis the general population, an overture to external validity was made by seeking replication through a probability sample of the general population of the state of Florida. Prior research suggests that fairness estimates may vary across populations (Gorman and Kehr 1992). The survey format precluded exact replication, but the survey questions were able to capture the basic intent of experiment 5 .

As part of a larger random-digit telephone survey conducted by a university-based economic and business research center, respondents over the age of 18 were asked to answer a single question regarding profits and fair prices for several familiar store types and products. Table 6 describes the exact wording of the questions posed across respondents, the size of the sample for each question, and the mean responses.

Results. The results closely corresponded to those of experiment 5 . Respondents showed some good but mostly bad intuitions. The perceived nonsale markup for clothing items at a department store approached $100 \%$ of cost, as respondents estimated a $\$ 76.58$ price for an item that had a $\$ 40.00$ CGS. However, the estimated fair price was $\$ 58.16$. Fair price increased to $\$ 62.94$ when the store's labor and rent costs were cued but still remained well below the expected price. One speculation is that shoppers peg their fair price on the reduced price observed during sale periods (cf. Kahneman et al. 1986b), with the logic that the store should always sell at the reduced price if it can occasionally sell at that price.

The questions concerning overall profitability again show a lack of appreciation for market dynamics and competition. Although estimates trended in the same direction as the average price of goods at each of three store types, overall profit estimates were extreme. For example, the profit earned by grocery stores is commonly cited at $1 \%-2 \%$ (Food Marketing Institute 2001) whereas the sample's estimate was $27.5 \%$. It appears that people do not spontaneously or fully appreciate retailer costs when judging fair prices. Profit is viewed as constituting a large proportion of the selling price. These results are consistent with experiments 2 and 3 , which found that profit dominated other attributions for the expected price differences at expensive and inexpensive stores.

Experiments 5 and 6 attempted to adjust perceptions of profit through a very modest manipulation of non-CGS costs. The effect on profit estimation was also modest. Although it is questionable whether consumers spontaneously consider such costs at all when making real-world assessments, the following experiments attempted to dampen profit overestimation further through the use of different and more detailed cost cues.

\section{Experiment 7: Cueing Detailed Costs}

The previous study examined the effect of a general labor cue; the present study examined deeper cueing of the same category. From an availability or anchoring perspective, cueing components of a cost category should increase cost estimates and reduce profit estimates. However, prior research in the domain of probability estimation has reported mixed results (e.g., Fischhoff, Slovic, and Lichtenstein 1978; van Schie and van der Pligt 1994). The present experiment used a three-group between-subjects design that manipulated the labor cue at three levels. Participants either received no specific cue, a labor cue, or a detailed labor cue and were asked to estimate labor (in the cued conditions), CGS, other costs, and profit (out of $\$ 1$ ). The detailed labor version scenario read as follows:

We are interested in your impression of finances at a major department store. We would like your estimate of the pro-

TABLE 6

PRICE AND PROFIT ESTIMATES FROM A PROBABILITY SAMPLE: EXPERIMENT 6

\begin{tabular}{|c|c|c|c|}
\hline Question & $n$ & $\begin{array}{c}\text { Mean } \\
(\$)\end{array}$ & $\begin{array}{l}\text { SD } \\
(\$)\end{array}$ \\
\hline $\begin{array}{l}\text { If a fancy department store pays } \$ 40 \text { to a manufacturer for a woman's blouse, } \\
\text { what would be a fair price for the store to charge you? } \\
\text { If a fancy department store pays } \$ 40 \text { to a manufacturer for a woman's blouse, } \\
\text { what would be a fair price for the store to charge you, keeping in mind the }\end{array}$ & 593 & 58.16 & 17.12 \\
\hline $\begin{array}{l}\text { store must cover such costs as rent and payroll? } \\
\text { If a fancy department store pays } \$ 40 \text { to a manufacturer for a woman's blouse, } \\
\text { how much do you think the store charges you for the blouse when it is not }\end{array}$ & 524 & 62.94 & 21.87 \\
\hline $\begin{array}{l}\text { on sale? } \\
\text { For each } \$ 100 \text { a fancy department store makes in sales, how many dollars do }\end{array}$ & 491 & 76.58 & 33.78 \\
\hline you think are left over in pure profit after the store has covered all its costs? & 775 & 33.09 & 29.18 \\
\hline . . . for a discount store . . . & 538 & 30.24 & 29.36 \\
\hline . . . for a grocery store . . . & 671 & 27.52 & 20.52 \\
\hline
\end{tabular}


portion of a department store's revenue that goes to cover the cost of goods sold, the proportion that goes to cover all other remaining costs, and how much is left as profit (after taxes). On the lines below, you see a simplified version of a major department store's income statement. Consider one dollar of revenue. What is your estimate of how much of each dollar in sales is allocated to each of these categories?

Cost of Goods Sold (money paid to suppliers for goods sold in the store)

Cost of Labor

- salaries and commissions paid to fulltime sales associates

- salaries and bonuses paid to managers

- salaries paid to other staff

- all other labor costs

All Other Costs

Profits

Total

After estimating these categories, participants also provided fairness ratings (on a seven-point scale).

Results. Labor estimates increased as a function of the detail in the labor cue $(F(1,89)=12.33, p<.001)$. As table 7 indicates, cueing general labor reduced other cost estimates $(F(1,133)=24.33, p<.001)$, as did the detailed labor cue $(F(1,133)=38.95, p<.001)$. The general labor cue did not significantly reduce profits relative to the no-cue control group, although the means are directional $(F(1,133)=$ $1.56, p>.20)$. However, a detailed labor cue did reduce profit estimates significantly $(F(1,133)=18.03, p<.001)$. Mirroring the changes in profit, fairness judgments were unaffected by the general labor cue $(F<1)$ but were higher relative to the no-cue control group when additional detail was provided $(F(1,132)=6.33, p=.01)$. These results suggest that participants may have partially and spontaneously taken labor into account when judging profits and fairness. Consistent with experiment 5 , cueing general labor also reduced CGS estimates relative to the control group $(F(1,133)=5.61, p=.02)$; that is, participants borrowed from CGS when labor was cued. However, there was directionally less borrowing from CGS when a detailed labor cue was provided $(F(1,133)=2.42, p=.12)$. In fact, CGS estimates in the detailed-cue condition did not differ from the no-cue condition $(F<1)$, indicating that participants were willing to extract the costs of labor from profit only when costs of labor to the firm were made very explicit.

These results demonstrate several points. As observed previously, participants did not always respond appropriately to cueing of costs. If they had, estimates of CGS would not have declined and profits would have held steady when general labor was cued. However, participants were not intransigent. Detailed cueing prompted a more accurate reallocation of costs and profit, albeit not nearly to the extent necessary. Also, as reported in experiment 3, fairness judgments declined as profit estimates increased. In combination, it appears that consumers' perceptions of costs, profits, and fairness are susceptible to influence.
TABLE 7

\section{COST AND PROFIT ESTIMATES (OUT OF \$1) AND FAIRNESS RATINGS AS A FUNCTION OF CUE SPECIFICITY: EXPERIMENT 7}

\begin{tabular}{lclc}
\hline \hline Cue & No cue & Labor cue & Detailed labor cue \\
\hline$n$ & 45 & 44 & 47 \\
Cost of good sold & $36.4(14.4)$ & $29.0(13.6)$ & $33.8(16.0)$ \\
Other costs & $22.1(12.4)$ & $13.0(6.7)$ & $10.7(5.7)$ \\
Cued costs &... & $21.1(10.4)$ & $29.2(11.5)$ \\
Profit & $41.5(18.6)$ & $37.0(17.4)$ & $26.3(15.3)$ \\
Fairness & $3.8(1.2)$ & $4.0(1.3)$ & $4.4(1.1)$ \\
\hline
\end{tabular}

\section{Experiment 8: Not All Costs Are Equal}

The research thus far is equivocal with regard to the question of spontaneity. On the one hand, the lack of a general labor-cue effect in experiment 7 suggests that labor may be considered spontaneously-at least in the context of an explicit decomposition task. On the other hand, profit estimates can be moderated by an unrealistically heavy-handed version of the labor cue. Leaving aside the fact that consumers are rarely faced with a decomposition task and therefore are less likely to be mindful of the firm's costs in the real world, the question of spontaneity of other costs remains. Of all non-CGS costs, labor intuitively seems most salient. We hypothesized that non-CGS and nonlabor costs are unlikely to be considered spontaneously and therefore are more likely to influence cost, profit, and fairness estimates when cued. We selected three categories: labor (a large category that is intuitively salient), rent (a smaller cost category that seems unlikely to be spontaneously taken into account), and markdowns (an important practice in store pricing that affects profits but also seems unlikely to be considered spontaneously). The experiment used a 3 (Cue: labor vs. rent vs. markdowns) $\times 2$ (Repeated Judgment: before and after cueing) mixed design. The initial scenario read as follows:

We are interested in your impression of finances at a major department store. We would like your estimate of the proportion of department store revenue that goes to cover cost of good sold (money paid to suppliers for goods sold in the store), the proportion that goes to cover all other remaining costs, and how much is left as profit (after taxes). On the lines below, you see a simplified version of a major department store's income statement. Consider one dollar of store revenue. What is your estimate of how much of each dollar in sales is allocated to each of these categories?

Cost of Goods Sold:
All Other Costs:
Profits:
Total

After estimating these categories, participants provided fairness ratings (on a seven-point scale). The repeat judgment (in the rent cue condition) was elicited as follows: 
One cost that stores have is the cost of property leases (rent paid on buildings leased for store use). You may or may not have taken property leases and other costs fully into account as part of the "All Other Cost" category in your previous estimate of a department store's finances. On the lines below, you see another version of a major department store's income statement. This statement breaks out property lease costs separately from all other costs. Consider one dollar of store revenue. What is your estimate of how much of each dollar in sales is allocated to each of these categories?

Other participants were prompted to consider "the cost of markdowns (price reductions used to move merchandise)" or "the cost of labor (salaries, commissions and bonuses paid to associates, managers and other staff)." After the rent, labor, or markdown cue, participants estimated CGS, the cued category, other costs, and profit, and then rejudged price fairness.

Results. All three of the cues increased estimates of non-CGS costs and decreased estimates of CGS (relative to no change, as reported in table 8 ). The adjustment to CGS was greater after cueing labor than after cueing markdown and rent $(F(1,54)=4.33, p=.04)$; the latter did not differ from each other $(F<1)$. Regardless of cue, profit estimates were still quite high, ranging from $33 \%$ to $40 \%$. The adjustment to profit was smaller after cueing labor than after cueing markdowns and rent $(F(1,54)=8.16, p<.01)$; the latter differed marginally from each other $(F(1,54)=$ $3.66, p=.06$ ). Profit was reduced by markdown and rent cues but not labor (relative to no change). Fairness ratings mirrored this pattern of means directionally $(F<1)$; that is, fairness ratings rose after cueing markdowns and rent but not labor (relative to no change).

Considering the cues separately, labor showed the nowexpected pattern. A labor cue produced little change in profit but did produce a decline in CGS. Thus, while acknowledging the labor cost, participants were more prone to reduce variable costs than profit. In the cases of rent and markdowns, however, there was less borrowing from CGS and a consequent lowering of profit estimates. These results demonstrate that nonobvious categories are not generated spontaneously and that cueing of such costs does produce a reasonably rational response in terms of CGS and profit estimates. From a methodological perspective, the different results obtained across cues demonstrate that the results from the previous studies are not an anchoring artifact of merely providing participants with another category to estimate.

\section{Discussion}

We conclude that people lack accurate mental models of the costs associated with a product and therefore are unable to generate these cost categories spontaneously. This explanation is consistent with analogous findings that people experience difficulty decomposing tasks (MacGregor and Armstrong 1994) and unpacking hypotheses (Tversky and Koehler 1994) when making subjective estimates. Moreover, research on hypothesis generation suggests that people prematurely terminate the generation process (Shaklee and Fischhoff 1982) and underestimate the other nongenerated hypotheses (Gettys and Fisher 1979; Gettys, Mehle, and Fisher 1986). Our conclusion is further supported by a follow-up study that examined the effect of broadening the number of cued cost categories. Participants were given either a long list (CGS, Labor, Rent, Maintenance, Administration, and Other Costs) or short list (CGS and Other Costs) of cost categories and were asked to provide numerical estimates for costs and profit for a women's blouse at a department store. When more costs were cued, total cost estimates increased $(F(1,60)=6.94, p=.01)$ and profit estimates declined $(F(1,60)=13.57, p<.001)$. However, even this extreme and tactically dubious manipulation only reduced profit estimates from $31 \%$ to $20 \%$.

Aside from their inability to generate cost categories, consumers also may have inaccurate perceptions of those costs. In essence, decomposing the task is unlikely to improve overall estimation accuracy if the component tasks are no easier than the fair price estimate itself. Our results do show, however, that increases in perceived cost also increased perceived fairness. A similar relationship between profit and fairness was observed in experiments 3 and 7 . A reasonable question to ask, however, is whether this relationship between costs and fairness is robust across cost categories. This question was investigated in the following study.

TABLE 8

CHANGE IN COST AND PROFIT ESTIMATES AND FAIRNESS RATINGS AS A FUNCTION OF COST CUE: EXPERIMENT 8

\begin{tabular}{|c|c|c|c|c|c|}
\hline Cue & $n$ & $\begin{array}{l}\text { Change in cost of good } \\
\text { sold }\end{array}$ & Change in other costs & Change in profit & Change in fairness \\
\hline $\begin{array}{l}\text { Labor } \\
\text { Rent }\end{array}$ & 19 & $\begin{array}{c}-6.1^{*}(8.7) \\
t(18)=3.06, p<.01 \\
-2.4^{*}(5.6)\end{array}$ & $\begin{aligned} & +7.9^{*}(9.3) \\
\pi(18)= & 3.60, p<.01 \\
& +7.5^{*}(7.7)\end{aligned}$ & $\begin{array}{c}-1.8(5.1) \\
t(18)=1.54, p=.07 \\
-5.1 *(7.7)\end{array}$ & $\begin{aligned} & +.16(.60) \\
t(18)= & 1.16, p=.13 \\
& +.35^{*}(.81)\end{aligned}$ \\
\hline Markdowns & 18 & $\begin{aligned} t(19)= & 1.91, p=.04 \\
& -2.2^{*}(4.3) \\
t(17)= & 2.17, p=.02\end{aligned}$ & $\begin{aligned} t(19) & =4.34, p<.01 \\
& +11.4^{\star}(6.6) \\
t(17) & =7.32, p<.01\end{aligned}$ & $\begin{aligned} t(19)= & 2.91, p<.01 \\
& -9.2^{*}(6.7) \\
t(17)= & 5.81, p<.01\end{aligned}$ & $\begin{aligned} t(19)= & 1.93, p=.03 \\
& +.33^{*}(.59) \\
t(17)= & 2.37, p=.01\end{aligned}$ \\
\hline
\end{tabular}

*Significantly different from zero $(p<.05)$. 
TABLE 9

COST AND PROFIT ESTIMATES (OUT OF \$1) AND FAIRNESS RATINGS AS A FUNCTION OF CUEING PROMOTIONAL COSTS: EXPERIMENT 9

\begin{tabular}{|c|c|c|c|c|c|c|}
\hline Promotion & $n$ & Cost of good sold & Promotion costs & Other costs & Profit & Fairness \\
\hline Uncued & 43 & $\begin{array}{c}16.37 \\
(10.91)\end{array}$ & . & $\begin{array}{c}32.21 \\
(20.31)\end{array}$ & $\begin{array}{c}51.42 \\
(23.11)\end{array}$ & $\begin{array}{c}3.33 \\
(1.52)\end{array}$ \\
\hline Cued & 37 & $\begin{array}{c}14.51 \\
(10.18)\end{array}$ & $\begin{array}{c}36.00 \\
(20.43)\end{array}$ & $\begin{array}{l}11.41 \\
(7.00)\end{array}$ & $\begin{array}{c}38.08 \\
(21.75)\end{array}$ & $\begin{array}{l}3.05 \\
(.97)\end{array}$ \\
\hline
\end{tabular}

\section{Experiment 9: Unfair Costs}

The principle of dual entitlement suggests that firms are entitled to raise prices in the face of increased costs. However, intuition and the popular press suggest that not all costs are deemed appropriate, and it would be folly to educate consumers about them. For example, educating consumers about the large bonuses paid to a firm's senior executives seems unlikely to improve consumer perceptions of the fairness of a firm's prices. Consumer reaction to other costs incurred routinely by firms is less obvious.

As an initial test, we ran a pilot study that manipulated the locus of a firm's costs. We found that a firm described as devoting $40 \%$ of its revenue to labor and $20 \%$ to all other costs was perceived as fairer than a firm that devoted $40 \%$ of its revenue to promotion and $20 \%$ to all other costs $(F(1,36)=6.81, p=.01)$ - even when the net margin at each firm was equal and low (5\%). Thus, not all costs are fair nor, as also shown in experiment 4 , are equal profits equally fair.

This finding was probed further in the present study that also examined spontaneity. Nike is an interesting example of a firm that manufactures a product with relatively low CGS and labor costs but relatively high promotional costs. Indeed, Nike has received a great deal of publicity regarding its expensive promotional and sponsorship deals and therefore should provide a strong test of spontaneity.

Method. The experiment used a 2 (Promotions Cue) $\times$ 2 (Measurement Order) between-subjects design. Participants either were cued or not cued about Nike's promotional spending. When cued, promotion appeared as a separate line item; in the uncued condition, there was no mention of promotional costs. Fairness was measured either before or after profit estimation. The stimulus scenario (from the cued, profit-first condition) read as follows:

As you know, Nike is a leading manufacturer of sports apparel, producing over 70 million pairs of shoes per year in its factories. We would like your estimate of the proportion of Nike's revenue that goes to cover material costs, the proportion that goes to cover promotional costs (including advertising and sponsorship) and the proportion that goes to cover all other remaining costs, as well as how much is left as Nike's profit (before taxes). On the lines below, you see a simplified breakdown of a Nike income statement. Consider one dollar of revenue. What is your estimate of how much of each dollar in sales is allocated to each of these categories?

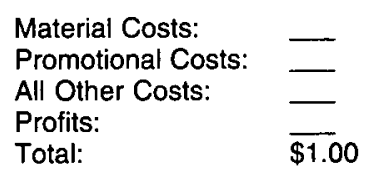

These participants then assessed the fairness of Nike prices on a seven-point scale.

Results and Discussion. As expected, fairness was lower when costs and profits were estimated first $(F(1,75)=5.73, p=.02)$ but order did not interact with cueing for any of the measures of concern (all $F$ 's $<1$ ). With regard to the measures of primary interest (see table 9 ), cueing of promotions significantly reduced estimates of profit $(F(1,76)=6.81, p=.01)$ and other costs $(F(1,76)=37.21, p<.001)$ but had no effect on CGS estimates $(F<1)$. Thus, promotional costs, even for a heavily promoted brand such as Nike, may not be spontaneously considered in their entirety. Moreover, the promotional cue had no effect on fairness ratings $(F<1)$, although fairness was directionally lower when promotional costs were cued. Intuition and the notion of dual entitlement (as well as many of our previous results) suggest that perceived fairness should rise as profits are consumed by costs. Clearly, price fairness judgments are guided by more than a simplistic view of entitlement. Different-yet legitimate-strategies for achieving competitive advantage in the marketplace are not viewed as equally fair, even when overall profit margin is held constant.

Taken together, these experiments suggest that consumers may possess beliefs inconsistent with the workings of a competitive marketplace. Profits are viewed as high and sticky; many costs appear to be largely ignored; and, some costs are viewed as fairer than others.

\section{THE TRANSACTION SPACE}

We have developed a "transaction space" to place the preceding experiments in context and to illustrate the potential for subsequent research (see fig. 1). A point in this space represents product $\mathrm{j}$ sold by firm $\mathrm{k}$ in the time period $t$ to the $i$ th consumer (i.e., Transaction ${ }_{i j k}$ ). For simplicity, 
FIGURE 1

TRANSACTION SPACE FOR THE $\Pi$ TH CONSUMER

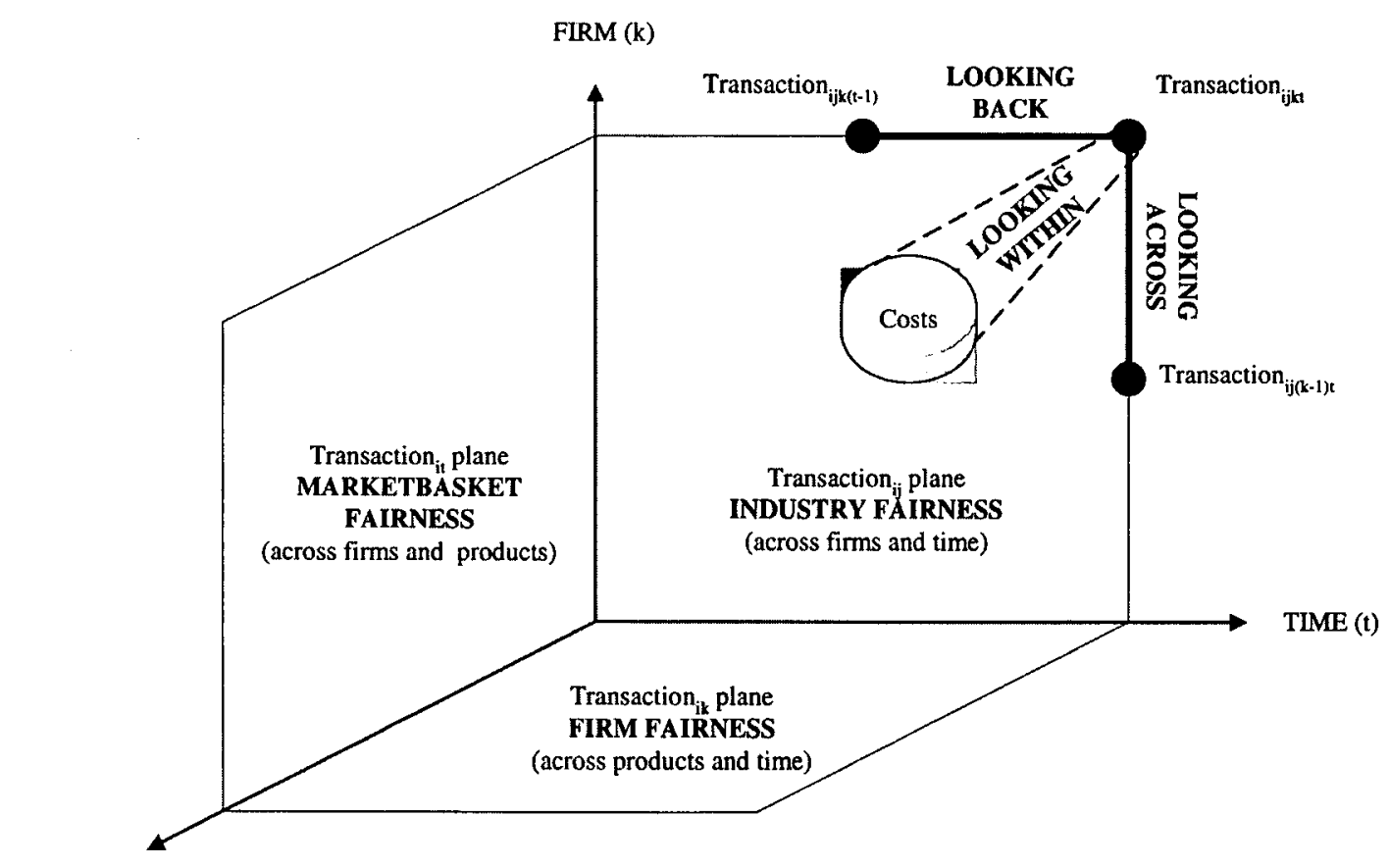

PRODUCT (j)

we have dropped the fourth dimension, the consumer, from the graphical representation in the figure. A price is associated with each transaction point. As we have shown, consumers can judge fairness by looking back along the time axis and comparing the price of a specific transaction (i.e., Transaction $_{\mathrm{ijk}}$ ) to a past price (i.e., Transaction ${ }_{\mathrm{ijk}(\mathrm{t}-1)}$ ). Alternatively, consumers can judge price fairness by looking across the firm axis to a competitor's price (i.e., Transaction $\left._{\mathrm{ij}(\mathrm{k}-1) \mathrm{t}}\right)$ or by looking within at the costs associated with Transaction ${ }_{\mathrm{ijk}}$.

A common characteristic of all studies reported thus far is that participants rendered judgments about a single transaction, that is, a point in the transaction space. However, given the increasing attention paid to customer loyalty and customer relationship management (Oliver 1999; Reinartz and Kumar 2000), it may be useful to consider how consumers judge fairness for a set of transactions, that is, multiple points (such as a line or plane) in the transaction space. In the case of a single transaction, another transaction in the space may serve as a reference point for comparison purposes. In the case of multiple transactions, individual transactions in the space may be psychologically linked (cf. Gourville and Soman 1998), and fairness may be judged at the aggregate level. The four-dimensional transaction space permits us to expand our investigation of price fairness to include both comparative and aggregate judgments across consumers, products, firms, and time. To illustrate, the following experiment examines a single and narrow instantiation of aggregation, that is, repeat purchase by a customer over time (represented by a line Transaction ${ }_{\mathrm{ijk}}$ ).

\section{Experiment 10: Repeat Transactions for Goods versus Services}

For simplicity, assume that a firm's non-CGS expenses are negligible. Dual entitlement suggests that a reasonable markup over CGS would be perceived as fair. Although never addressed, the assumption is that consumers should be willing to pay the same approximate price over multiple purchases if the cost to the vendor also varies little across transactions. However, consider the case of repeat payment for a single item - as when a product is rented rather than purchased-and neither the price nor the cost to the vendor change. For the vendor, profit is obtained from each transaction. Given enough transactions, the cumulative rental price will exceed the vendor's purchase price of the good (CGS). Thus, a decline in the perceived fairness of the product rental price may be observed as the number of transactions increases.

The present experiment compares the perceived fairness of a transaction framed as a good versus service as a function of purchase frequency. Even when comparable utility is provided in the good and service frames, perceptions of fairness may vary due to a lack of CGS for the latter. Thus, the service condition may be viewed as a control against which the product rental condition is compared. 
Method. The experiment used a 2 (Service/Good Frame) $\times 2$ (Single/Multiple Transactions) between-subjects design. Participants were asked to judge fairness of prices charged for entertaining a child once or 20 times, and the entertainment was framed as a service or a good. The scenario for a single transaction read as follows:

Imagine that you are a working mother with a young schoolage child. During the next month, you will be working on an important project. The project requires you to work late at the office for one extra hour once during the month. You need to find some entertainment for your child during this time. You don't have any other options.

In the multiple transaction condition, the scenario was modified as follows:

Imagine that you are a working mother with a young schoolage child. During the next month, you will be working on an important project. The project requires you to work late at the office for one extra hour each day (i.e., 20 times during the month). You need to find some entertainment for your child during this time. You don't have any other options.

All participants then read about a solution to their problem.

You discover a local company called "Fun4Kids." It is a local reputable firm that provides entertainment for children under adult supervision to ensure safety. In one of Fun4Kids' programs, an adult entertains your child with a board game. The program comes highly recommended-other parents who use the program frequently say their child loves playing the game with the adult and never tires of it. Your child has tried the game and really loved it.

Participants in the service condition were then asked (with the multiple transaction amount shown in square brackets):

The charge for the adult's services is $\$ 15$, for a total price of $\$ 15[\$ 300]$ to entertain your child. How fair do you think this price is?

In the good condition, the same transaction was framed as rental of a good.

The charge for board game rental is $\$ 15$, for a total price of $\$ 15[\$ 300]$ to entertain your child. How fair do you think this price is?

Fairness was then measured on a seven-point scale.

Results and Discussion. An ANOVA revealed a main effect of transaction $(F(1,55)=39.70, p<.001)$ that was qualified by an interaction with frame $(F(1,55)=6.36$, $p=.02$ ). As the pattern of means in table 10 indicates,
TABLE 10

PRICE FAIRNESS RATINGS FOR SERVICES VERSUS GOODS FOR SINGLE VERSUS REPEATED TRANSACTIONS

\begin{tabular}{llll}
\hline \hline Frame & \multicolumn{1}{c}{ Transaction } & $n$ & Fairness rating \\
\hline Good & Single (1 use) & 14 & $5.86(1.17)$ \\
Good & Repeated (20 uses) & 16 & $2.69(1.30)$ \\
Service & Single (1 use) & 14 & $5.36(1.65)$ \\
Service & Repeated (20 uses) & 15 & $4.00(1.36)$ \\
\hline
\end{tabular}

fairness ratings declined more from a single transaction to multiple transactions for goods $(F(1,28)=48.58, p<$ $.001)$ than for services $(F(1,27)=5.88, p=.02)$. Note that the good condition subsumed the service condition, inasmuch as the good rental included not only the game but also the adult's labor. Thus, the low perceived fairness in the multiple-good condition seems particularly inappropriate.

Our previous studies showed that the fair price of a good is based partly on estimated CGS. The present study shows that multiple purchases of a good are deemed unfair vis-àvis multiple purchases of a service, even when expected value of the good and service to the consumer is high and equal. From the firm's perspective, pricing of goods and services may be differentially constrained by fairness. From a public welfare perspective, consumers may be insensitive to the larceny involved in failing to pay for products and services that have few obvious tangible costs-as seen recently in the so-called sharing of music via the internet (cf. Hsee, Nunes, and Weber 2002). The true scope of this issue is too broad to be treated systematically here, but we believe further investigation of differences in perceived price fairness for goods versus services is merited.

\section{GENERAL DISCUSSION}

Taken together, our findings suggest that consumer knowledge of prices, profits, and costs contribute to perceptions of price unfairness in the marketplace. When looking back in time, consumers systematically underestimate the effects of inflation, even when provided with explicit inflation rates, current prices, and historical data. When looking across competitors, consumers tend to attribute store price differences to profit rather than costs. Even after controlling for profit levels, consumers take into account how profits are made when comparing prices. Some marketing strategies (e.g., margin vs. volume strategies) may be judged as relatively unfair, even when beyond the store's control. From a consumer's perspective, price differences appear fair(est) only if they can be attributed to quality differences. However, when consumers look within the firm and assess costs, cost categories beyond the cost of goods sold are likely to be ignored. Cueing other costs (e.g., more cost categories, more details about costs, and less obvious costs) prompts adjustment in the appropriate direction; nonetheless, profit estimates appear to be sticky and high, and some costs (e.g., 
promotional costs) can stimulate feelings of unfairness. Finally, perceived fairness is lower for repeated rental of a good compared to an equivalent service, illustrating a constraint on fair pricing when judged in aggregate.

Our intent is not to suggest that consumers routinely entertain thoughts about vendor profits or price fairness. However, when such thoughts do occur, perceptions may be shaped by unfavorable comparisons to the reference points investigated here-and those yet to be explored.

\section{Future Research}

Transaction Fairness. A large opportunity exists to examine the issue of perceived price fairness in ways that go beyond the present results and the pioneering findings on dual entitlement. For example, we suspect that fairness perceptions may be driven not only by comparisons to past prices, competitor prices, and perceived costs but also to prices paid by other consumers (i.e., by comparing Transaction $_{\mathrm{ijkt}}$ to Transaction ${ }_{(\mathrm{i}-1) \mathrm{jk} 1}$ in the transaction space). Consumers may be particularly sensitive to this reference point when price discrimination exists-as at a movie (senior vs. adult ticket prices), on a car lot (as a result of negotiation), and in the air (full fare vs. economy tickets). When is price discrimination acceptable to the consumer and on what basis? More generally, under what conditions will consumers be sensitive to comparison(s) across consumers, products, firms, and/or time, and how is fairness affected if multiple reference points are salient to the consumer? The transaction space emphasizes the importance of the frame of reference when consumers judge price fairness for a single transaction. The importance of understanding the reference point(s) used by consumers to judge price fairness should be self-evident not only to marketers who develop pricing strategies but also to consumer researchers interested in consumer knowledge, purchase satisfaction, and public welfare.

Aggregate Fairness. The transaction space also suggests avenues for future research regarding the issue of aggregation. Experiment 10 examined a single and narrow case of aggregation in which pricing for repeated rental of a good was constrained. In this instance, fairness limits the price that can be charged and profits that can be made over the lifetime of the good. We speculate that fairness constraints may also exist for goods and services over the lifetime of the customer. That is, the amount of profit earned by a firm over multiple transactions with a single customer may be limited by fairness considerations (compared to the equivalent number of transactions over multiple customers). In fact, experiment 10 showed that fairness declined over repeat transactions for both goods and services. Contrary to popular wisdom, long-time customers may be more sensitive to price and therefore less profitable to firms (cf. Reinartz and Kumar 2000 ). When repeat purchases of a firm's product by a customer over time constitute the set of transactions (i.e., a line Transaction ${ }_{i j k}$ ), fairness constraints in the aggregate should have important implications for loyalty pricing. When the purchase of a bundle of products from a firm by a customer constitute the set of transactions (i.e., a line Transaction ${ }_{\mathrm{ik}}$ ), fairness constraints in the aggregate should have important implications for bundled pricing. In both cases, sensitivity to the total amount of profit extracted from a single customer through a set of transactions with a single firm drive aggregate fairness judgments and may have implications for relationship marketing and customer lifetime value.

Whereas loyalty and bundling illustrate the potential usefulness of aggregation across a single dimension in the transaction space, other situations involve aggregation across multiple dimensions. For example, a consumer may hold perceptions of price fairness at the industry level (e.g., that gasoline prices are unfair), which are an aggregate of price fairness judgments across firms and time for a specific product (i.e., a Transaction ${ }_{i j}$ plane). Firm-level price fairness perceptions (e.g., that Wal-Mart has fair prices) also may be formed by aggregating across products and time for a specific firm (i.e., a Transaction ${ }_{i k}$ plane). Surveys that measure consumer perceptions of fairness across firms and products at a point in time provide a snapshot of market basket fairness (i.e., a Transaction ${ }_{\text {it }}$ plane). Future research could investigate the formation of price fairness judgments at these aggregate levels and, in turn, their relationship to aggregate or cumulative indices of customer satisfaction.

Consumer Knowledge. Although consumer research has historically investigated product knowledge and expertise (cf. Alba and Hutchinson 1987), Wright (2002) has recently called for consumer research on "marketplace metacognition" (i.e., everyday market-related thinking). In our view, research on price fairness bridges the gap between product- and market-level knowledge, 'inasmuch as judgments about transaction fairness reflect consumer beliefs about marketplace dynamics. For example, the present research suggests that consumers have a schema for judging price fairness. Higher prices are attributed to profit (rather than quality or other costs), and price differences arising from some marketing strategies are judged as relatively unfair. Moreover, consumers appear to have a poor appreciation of the costs faced by firms. Many costs are ignored and some costs are viewed as unfair, leading to high and sticky profit estimates that contribute to perceptions of unfairness. Unlike some previous research demonstrating appropriate skepticism regarding marketers' tactics and motivations, the present findings suggest that consumer skepticism may derive from inappropriate beliefs about the competitive marketplace. However, both prior research and the present findings on marketplace cognition suggest the potential for buyer-seller conflict, mistrust, and consumer dissatisfaction.

[Received November 2001. Revised July 2002. David Glen Mick served as editor and William O. Bearden served as associate editor for this article.] 


\section{REFERENCES}

Alba, Joseph W. and J. Wesley Hutchinson (1987), "Dimensions of Consumer Expertise," Journal of Consumer Research, 13 (March), 411-454.

Bates, John M. and Andre Gabor (1986), "Price Perception in Creeping Inflation: Report on an Enquiry," Journal of Economic Psychology, 7 (September), 291-314.

Bearden, William O., Jay P. Carlson, and David M. Hardesty (2003), "Using Invoice Price Information to Frame Advertised Prices," Journal of Business Research, in press.

Bies, Robert J., Thomas M. Tripp, and Margaret A. Neale (1993), "Procedural Fairness and Profit Seeking: The Perceived Legitimacy of Market Exploitation," Journal of Behavioral Decision Making, 6 (December), 243-256.

Blinder, Alan S. (1991), "Why Are Prices Sticky? Preliminary Results from an Interview Study," American Economic Review, 81 (May), 89-96.

Briesch, Richard A., Lakshman Krishnamurthi, Tridib Mazumdar, and S. P. Raj (1997), "A Comparative Analysis of Reference Price Models," Journal of Consumer Research, 24 (September), 202-214.

Business Week (2000), "How Business Rates: By the Numbers," September 11, 148-149.

Campbell, Margaret C. (1999), "Perceptions of Price Unfairness," Journal of Marketing Research, 36 (May), 187-199.

Estelami, Hooman, Donald R. Lehmann, and Alfred C. Holden (2001), "Macro-Economic Determinants of Consumer Price Knowledge: A Meta-analysis of Four Decades of Research," International Journal of Research in Marketing, 18 (December), 341-355.

Fischhoff, Baruch, Paul Slovic, and Sarah Lichtenstein (1978), "Fault Trees: Sensitivity of Estimated Failure Probabilities to Problem Representation," Journal of Experimental Psychology: Human Perception and Performance, 4 (May), 330-344.

Food Marketing Institute (2001), "Supermarket Facts: Industry Overview 2000," August, http://www.fmi.org/facts_figs/ superfact.html.

Frey, Bruno S. and Werner W. Pommerehne (1993), "On the Fairness of Pricing-an Empirical Survey among the General Population," Journal of Economic Behavior and Organization, 20 (April), 295-307.

Gettys, Charles F. and Stanley Fisher (1979), "Hypothesis Plausibility and Hypothesis Generation," Organizational Behavior and Human Performance, 24 (August), 93-110.

Gettys, Charles F., Thomas Mehle, and Stanley Fisher (1986), "Plausibility Assessments in Hypothesis Generation," Organizational Behavior and Human Decision Processes," 37 (February), 14-33.

Gorman, Raymond F. and James B. Kehr (1992), "Fairness as a Constraint on Profit Seeking: Comment," American Economic Review, 82 (March), 355-358.

Gourville, John T. and Dilip Soman (1998), "Payment Depreciation: The Behavioral Effects of Temporally Separating Payment from Consumption," Journal of Consumer Research, 25 (September), 160-174.

Grewal, Dhruv and Julie Baker (1994), "Do Retail Store Environments Affect Consumers' Price Acceptability? An Empirical Investigation," International Journal of Research in Marketing, 11 (March), 107-115.

Grewal, Dhruv, Kent B. Monroe and R. Krishnan (1998), "The Effects of Price-Comparison Advertising on Buyers' Percep- tions of Acquisition Value, Transaction Value, and Behavioral Intentions," Journal of Marketing, 62 (April), 46-59.

Harvey, Nigel and Fergus Bolger (1996), "Graphs versus Tables: Effects of Data Presentation Format on Judgmental Forecasting," International Journal of Forecasting, 12 (March), 119-137.

Hsee, Christopher K., Joseph C. Nunes, and Elke U. Weber (2002), "The Effects of Products' Cost Structure on Consumer Payment and Purchase Intentions," unpublished manuscript, University of Chicago, Graduate School of Business.

Jacobson, Robert and Carl Obermiller (1990), "The Formation of Expected Future Price: A Reference Price for Forward-Looking Consumers," Journal of Consumer Research, 16 (March), $420-432$.

Kahneman, Daniel, Jack L. Knetsch, and Richard H. Thaler (1986a), "Fairness and the Assumptions of Economics," Journal of Business, 59 (October), S285-\$300.

(1986b), "Fairness as a Constraint on Profit Seeking: Entitlements in the Market," American Economic Review, 76 (September), 728-741.

Katona, George (1975), Psychological Economics, New York: Elsevier Scientific.

Kemp, Simon (1987), "Estimation of Past Prices," Journal of Economic Psychology, 8 (June), 181-189.

(1991), "Remembering and Dating Past Prices," Journal of Economic Psychology, 12 (September), 431-455.

Lichtenstein, Donald R. and William O. Bearden (1989), "Contextual Influences on Perceptions of Merchant-Supplied Reference Prices," Journal of Consumer Research, 16 (June), 55-66.

MacGregor, Donald G. and J. Scott Armstrong (1994), "Judgmental Decomposition: When Does It Work?" International Journal of Forecasting, 10 (December), 495-506.

Martins, Marielza and Kent B. Monroe (1994), "Perceived Price Fairness: A New Look at an Old Construct," in Advances in Consumer Research, Vol. 21, ed. Chris T. Allen and Deborah Roedder John, Provo, UT: Association for Consumer Research, 75-78.

Mayhew, Glenn E. and Russell S. Winer (1992), "An Empirical Analysis of Internal and External Reference Prices Using Scanner Data," Journal of Consumer Research, 19 (June), $62-70$.

Monroe, Kent B. (1990), Pricing: Making Profitable Decisions, 2d ed., New York: McGraw-Hill.

Oliver, Richard L. (1999), "Whence Consumer Loyalty," Journal of Marketing, 63 (Special Issue), 33-44.

Oliver, Richard L. and John E. Swan (1989), "Equity and Disconfirmation Perceptions as Influences on Merchant and Product Satisfaction," Journal of Consumer Research, 16 (December), 372-383.

Piron, Robert and Luis Fernandez (1995), "Are Fairness Constraints on Profit-Seeking Important?" Journal of Economic Psychology, 16 (March), 73-96.

Rajendran, K. N. and Gerard J. Tellis (1994), "Contextual and Temporal Components of Reference Price," Journal of Marketing, 58 (January), 22-34.

Reinartz, Werner J. and V. Kumar (2000), "On the Profitability of Long-Life Customers in a Noncontractual Setting: An Empirical Investigation and Implications for Marketing," Journal of Marketing, 64 (October), 17-35.

Shaklee, Harriet and Baruch Fischhoff (1982), "Strategies of Information Search in Causal Analysis," Memory \& Cognition, 10 (November), 520-530. 
Sinha, Indrajit and Rajeev Batra (1999), "The Effect of Consumer Price Consciousness on Private Label Purchase," International Journal of Research in Marketing, 16 (September), 237-251.

Thaler, Richard (1985), "Mental Accounting and Consumer Choice," Marketing Science, 4 (Summer), 199-214.

Tversky, Amos and Derek J. Koehler (1994), "Support Theory: A Nonextensional Representation of Subjective Probability," Psychological Review, 101 (October), 547-567.

van Schie, Els C. M. and Joop van der Pligt (1994), "Getting an Anchor on Availability in Causal Judgment," Organizational Behavior and Human Decision Processes, 57 (January), 140-154.
Wagenaar, Willem A. and Sabato D. Sagaria (1975), "Misperception of Exponential Growth," Perception \& Psychophysics, 18 (December), 416-422.

Wagenaar, Willem A. and Han Timmers (1979), "The Pond-andDuckweed Problem: Three Experiments on the Misperception of Exponential Growth," Acta Psychologica, 43 (May), 239-251.

Wall Street Journal (1997), "Why Shoppers Think Food Is a Ripoff," March 6, B1.

Wright, Peter (2002), "Marketplace Metacognition and Social Intelligence," Journal of Consumer Research, 28 (March), 677-682. 
Copyright of Journal of Consumer Research is the property of Journal of Consumer Research, Inc. and its content may not be copied or emailed to multiple sites or posted to a listserv without the copyright holder's express written permission. However, users may print, download, or email articles for individual use. 